\title{
O imaginário europeu sob o fantasma da filiação: sobre a racialização da arte e sua história
}

\author{
Francielly Rocha Dossin ${ }^{*}$ \\ Universidade Federal de Santa Catarina. Florianópolis, Santa Catariana, Brasil
}

Michaud, Éric. Les invasions barbares: une généalogie de l'histoire de l'art. Paris: Gallimard, 2015, 320p.

"Nos pères les Germains", Montesquieu.

Éric Michaud é historiador da arte e diretor de estudos na Escola de Altos Estudos em Ciências Sociais em Paris (École des Hautes Études en Sciences Sociales, EHESS). Suas pesquisas giram em torno dos projetos artísticos que visaram a construção do novo homem, especialmente nos séculos XIX e XX. Há alguns anos tem se dedicado a compreender a distinção que a história da arte europeia, a partir do século XIX, fez entre norte e sul. Michaud pesquisa a criação dessa divisão, fundamentada por concepçóes nacionalistas e racializadas, a partir da leitura de autores como Wölfflin, Schlegel, Riegl, Courajod e Viollet-le-Duc.

Pouco conhecido no Brasil, Michaud ainda não obteve uma tradução de fôlego no país. A publicação mais próxima que dispomos é a argentina La estetica nazi — un art de la eternidade (Buenos
Aires: Adriana Hidago, 2009, 397p.), ${ }^{1}$ seu livro anterior. ${ }^{2}$ Nessa obra o historiador francês empenhou-se no estudo do projeto estético nacional-socialista alemáo, sendo exemplo cabal do uso da arte como prova da autoproclamada superioridade ariana. Michaud mostra como os usos da arte podem estar em posição contrária à "reconciliação" entre povos e como se dá o vínculo inseparável entre projetos políticos e estéticos. Como revela o subtítulo original, "Uma arte da eternidade", a arte nazista propunha uma negação do tempo e da história. A inspiração para essa negação vem do cânone atemporal atrelado à noção de raça na história da arte. Essa problemática, que também circunda o último livro lançado, é tratada com a mesma erudição de seus textos anteriores. As invasóes bárbaras: uma genealogia da história da arte ${ }^{3}$ é

${ }^{1}$ Un art de l'éternité. L'image et le temps du national-socialisme. Paris: Gallimard, 1996, 392p. (A obra contou também como uma tradução em língua inglesa: The Cult of Art in Nazy Germany. Trad. Janet Lloyd. Stanford: Stanford University Press, 2004, 276p.).

${ }^{2}$ Michaud é autor de outros livros que ainda não foram traduzidos para a língua estrangeira. Cf. <http://cehta.ehess.fr/index.php?/membres/membres-associes/163-eric-michaud $>$.

3 Algumas questóes centrais das quais o autor se

* Doutora em História Cultural pela Universidade Federal de Santa Catarina. E-mail: frandossin@gmail.com. 
uma publicação da coleção Nrf Essais da editora francesa Gallimard. Resultado de uma pesquisa conduzida em 2010 no Institute for Advanced Study (Universidade de Princeton) e financiada pela fundação franco-estadunidense Florence Gould Foundation Fund. Na obra, Éric Michaud demonstra como concepçôes raciais foram fundantes da história da arte como disciplina.

Para o autor, "a história da arte começou com as invasões bárbaras"4 (p. 11), uma afirmação forte, mas que não significa que a história da arte tenha começado nos séculos IV e $\mathrm{V}$ com as invasóes ao Império Romano, tampouco que a arte não possuísse história antes delas, mas sim que a disciplina só se fez possível quando, entre os séculos XVIII e XIX, as invasões começaram a ser entendidas e narradas como o “(...) evento decisivo pelo qual o Ocidente se engajou na modernidade, ou seja, tomou consciência de sua própria historicidade" (p. 11). A noção de que os bárbaros foram aqueles que destruíram a Europa clássica se inverte a partir do romantismo, momento em que passam a ser entendidos como aqueles que construíram o continente. Há nesse momento uma grande mudança na representação sobre o passado, criando-se uma grande oposição entre nórdicos (enérgicos e masculinos) e latinos (decadentes e femininos).

"Sobre um fantasma da filiação" é o título da introdução na qual o autor nos apresenta

ocupou no livro já tinham sido apresentadas em um artigo que publicou previamente na revista estadunidense October (n. 139, p. 59-76, inverno de 2012) sob o título "Barbarian Invasions and the Racialization of the Art History".

${ }^{4}$ Todas as citaçóes dos originais em língua estrangeira foram traduzidas por mim. as linhas gerais de sua obra, mostrando como a partir de 1800 os "bárbaros" começam a ser entendidos como "um povo" vigoroso, forte e criativo, que trouxe renovação e rejuvenescimento de todas as ordens através da "injeção" do novo sangue, das raças nórdicas, no "corpo" dos povos do Império decadente. O "gênio" nórdico" passa então a ser valorizado em detrimento da "latinidade".

A história da arte, que surge com um viés antirromano e anticlassicismo, é uma criação romântica, contemporânea à criação dos Estados-Naçóes e ao desenvolvimento do nacionalimo na Europa. Sua genealogia nos remete a uma determinada organização histórica e política inerente ao regime de visualidade racializado. As relaçóes entre história da arte e o modelo arqueológico e antropológico também ajudam a compreender como se deram as preocupaçóes com as origens étnicas e raciais, pois tinham objetivos semelhantes: determinar o pertencimento de origem de um objeto. A maior parte dos departamentos de história da arte nas universidades europeias é de "história da arte e arqueologia”, um exemplo dessa relação estreita entre ambas as disciplinas. Tanto a arqueologia quanto a história da arte tinham por tarefa associar “(...) seus objetos a grupos raciais se baseando em alguns signos visíveis" (p. 23). Essa procura por uma filiação, muitas vezes fantástica, levou a compreensão da estética como algo ligado ao sangue e à raça e serviu para que a "Europa projetas-

\footnotetext{
${ }^{5}$ A palavra gênio é utilizada aqui não no sentido de extraordinário talento, potência intelectual e/ou conhecimento, mas no sentido, mais comum em francês (génie), de características e qualidades próprias e distintivas de algo e/ou alguém.
} 
se no passado, seu projeto político nacional e racial” (p. 16). Assim, entendemos como “(...) a história da arte se inscreveu na grande narrativa da guerra das raças" (p. 16).

No primeiro capítulo, intitulado "Do 'gosto das naçôes' ao 'estilo de raça”, Michaud revela o caráter fantasmático, imaginário e confuso de noçóes basilares da disciplina, a exemplo das ideias de gosto e estilo que facilmente se confundiam com construções raciais. $\mathrm{O}$ "estilo" foi uma forma de visualizar, teorizar e hierarquizar diferenças. Daí teriam surgido divisôes como “arte latino-mediterrânea" e "arte nórdico-germânica”.

Já no segundo capítulo, intitulado "Automiméses e autorretrato dos deuses", Michaud mostra como se construiu determinada "leitura" da antiguidade (a mesma que posteriormente o projeto nazista portará, mas desta vez como uma caricatura). Um dos historiadores mais presente neste momento é Johann Joachim Winckelmann, considerado por muitos como o pai da história da arte (e da arqueologia científica). Winckelmann empreendeu uma busca pela pureza da arte antiga grega, ideal que para Michaud está intrinsecamente ligado à noção de pureza racial e à idealização da beleza humana, a exemplo da invenção do perfil grego. A análise dos textos de Winckelmann revela também o desenvolvimento de uma narrativa a-histórica e cristã. Nas palavras de Éric Michaud: “(...) foi, portanto, um modelo cristão que estruturou essa narrativa: o ideal era a encarnação do Espírito na história - mas na história da Grécia antiga” (p. 88), a arte grega espelhava, para Winckelmann, deuses autorretratados.

No terceiro capítulo, "As invasões bárbaras ou a racialização da história da arte", o autor aprofunda sua tese central na qual identifica na reinterpretação das invasões bárbaras o ponto decisivo da racialização da história da arte. Aqui vemos como o processo de "desbarbarização" dos povos outrora bárbaros e considerados sem arte e sem cultura possibilitou a inversão romântica e produziu o modelo histórico e cultural que agenciou a narrativa da disciplina história da arte. Ao longo da leitura somos introduzidos a conceitos como o de "tempo de incubação" (temps d'incubation), essenciais para compreender a visão evolucionista da arte. Segundo Michaud:

Ela [a noção de tempo de incubação] se comunicava com os conceitos de despertar, ${ }^{6}$ de reminiscência, e especialmente de sobrevivência que ele [Louis Courajod] lidava com talento para lançar constantemente pontes entre os planos biológico e cultural a fim de estabelecer uma natureza hereditária da transmissão das formas no espaço e no tempo. (p. 133)

Com a reabilitação dos povos bárbaros, surge outro grande inimigo das artes: o judeu. Se uma das tarefas da história da arte era mostrar como a arte representava um povo em suas qualidades e tradiçôes, o judeu, sem um território constante, ficava fora dessa narrativa. A visão comum era de que os judeus, egoístas, eram incapazes

\footnotetext{
${ }^{6}$ Réveil pode ser traduzida como "despertar", referindo-se a um processo de renascimento.
} 
artisticamente de se verem como um povo, uma nação. Eram iconoclastas e, portanto, insensíveis à beleza plástica. O judeu passa aos poucos a ser não só aquele que não tem arte, mas também o destruidor da cultura. Isso se dá principalmente depois da emancipação judaica. ${ }^{7}$ Esta tese está presente no quarto capítulo, "Um novo bárbaro: o judeu sem arte”.

No último capítulo, "O sangue dos bárbaros: estilo e hereditariedade", encontramos outros conceitos e problemas que dão suporte à tese do autor. A história da arte como evolução é observada na oposição da tatilidade antiga do sul à opticalidade moderna do norte e também nas disputas acerca das origens do gótico. São vários os diálogos entre a visão evolucionista e racializada da história da arte e o pensamento de autores como Conde de Gobineau, ${ }^{8}$ por exemplo.

Outro conceito que nos é apresentado é o de Kunstwollen (vontade da arte), desenvolvido por Aloïs Riegl. Para Michaud, o conceito de vontade da arte está imbuído de um essencialismo psicológico nacional e racial. Caso semelhante é o conceito de Rassencharakter (Caráter racial), que Wölfflin creditava ser o responsável pelo estilo de um povo. No entanto, Michaud não foi o primeiro a observar as estreitas relaçóes entre história da arte e teorias raciais. Meyer Shapiro já havia afirmado em 1936:

\footnotetext{
${ }^{7}$ Refiro-me aqui ao processo, que se deu entre o século XVIII até o século XX, de libertação dos judeus na Europa, expresso principalmente pela abolição de leis discriminatórias e pela conquista de direitos civis.

${ }^{8}$ Bastante conhecido no Brasil e pelos estudiosos das relaçôes raciais, pois, como diplomata, serviu no Brasil e seus escritos representam um resumo claro do racismo do século XIX.
}

As teorias raciais do fascismo apelam constantemente às tradiçóes artísticas (...). Onde, senão nos restos artísticos do passado, um nacionalista encontra as provas tangíveis de seu caráter racial imutável? Sua própria experiência se limita a uma ou duas geraçóes; somente os monumentos artísticos de seu país lhe asseguram que seus ancestrais eram como ele, e que seu próprio caráter é um legado permanente enraizado no seu sangue e no seu solo. Já faz um bom século que o estudo da história da arte tem sido usado para essas conclusóes. (Apud Michaud, 2015, p. 211)

É verdade que os historiadores da arte mais lidos, como Aby Warbug, não são diretamente citados, entretanto, Michaud problematiza a metodologia de Giovanni Morelli (sob o pseudônimo de Ivan Lermolieff), revisitado por Carlo Ginzburg, para desenvolver seu "paradigma indiciário", bastante utilizado por historiadores que tratam de arte, imagens, iconografia. Para Michaud, o método morelliano é outro exemplo de procura por indícios raciais e que faz parte de uma relação estabelecida anteriormente entre a "morfologia dos povos e as formas artísticas que produzem" (p. 64).

Nessa obra o conceito de raça tem uma conotação diversa da que ganha dianteira com o racismo científico. Por isso, sentimos falta de maiores contornos para o termo. No entanto, o autor está ciente dessas nuances e nos mostra que os termos raça, povo, nação, etnia foram utilizados de forma totalmente intercambiável por muitos 
dos autores que cita.

Para finalizar, cabe uma crítica relativa ao epílogo, intitulado "A etnização da arte contemporânea”. Nessas quatorze páginas, o autor defende que a crença de que uma arte representa um povo ou uma raça perdura não só nas classificações e divisóes museológicas por naçôes e origens, mas também no que ele chama de "etnicização da arte", que seria um fenômeno presente desde os anos 1950. Para ele, a universalidade abstrata, um dos princípios do mundo romano, continua a ser acusada de oprimir as singularidades dos diferentes povos; universalidade esta atualizada por meio da globalização. Tal queixa, para o autor, vem de uma visão romântica contra o que seria o poder normativo do classicismo. Michaud observa que o mercado de arte contemporânea tem sobrevalorizado as origens étnicas das obras de arte e dos artistas. Um dos casos lembrados pelo autor é a arte dos inuítes e como ela teria sido organizada pelo mercado de forma a valorizá-la, encerrando-a na constituição de um ideal de "pureza” de suas origens étnicas.

É possível observar um paralelo com a tese apresentada anteriormente, afinal, com a valorização de artistas fora do eixo Europa-Estados Unidos, não estaríamos assistindo a uma nova "reabilitação dos povos bárbaros"? Pode-se observar, por exemplo, como artistas africanos e afrodescendentes nas Américas e na Europa têm emergido em importantes espaços expositivos. Náo seria esse outro momento de "desbarbarização" dos povos outrora considerados sem arte e sem cultura? Lembramos especialmente o caso da África por ter sido o continente que por muito tempo foi consi- derado o exato oposto da Europa. E por isso, sem leis, sem cultura, sem história e sem arte.'

Se, por um lado, podemos afirmar com o autor que uma compreensão racial baliza a compreensão da arte na contemporaneidade, por outro, Michaud parece nivelar a produção contemporânea como sendo um produto do interesse "étnico". Nos últimos anos vêm ocorrendo uma maior participação de artistas oriundos de países chamados "periféricos" ao mundo da arte. É verdade que parte desses artistas conquista espaço através de rótulos relativos à origem, como, por exemplo, "arte latino-americana", "arte do mundo árabe” ou "arte africana”. Por outro lado, vários desses artistas procuram colocar essas noçôes em xeque. Os próprios artistas lutam para se livrar dessa etiqueta que acaba por enclausurá-los na função de porta-vozes de uma nação ou de um determinado povo. Muitos artistas questionam e criticam esse olhar balizado a partir do interesse pelo "exótico" ou por uma "diferença construída”. A poética desses artistas

\footnotetext{
${ }^{9}$ Lembro aqui o já bastante citado excerto da introdução de Fundamento geográfico da história Universal de Hegel: "A principal característica dos negros é que sua consciência não atingiu a intuição de qualquer objetividade fixa, como Deus, como leis, pelas quais o homem se encontraria com sua própria vontade, e onde ele teria uma ideia geral de sua essência. (...) $\mathrm{O}$ negro representa, como já foi dito, o homem natural, selvagem e indomável. Devemos nos livrar de toda reverência, de toda moralidade e de tudo o que chamamos de sentimento, para realmente compreendê-lo. Neles, nada evoca a ideia de caráter humano. (...) Entre os negros, os sentimentos morais são totalmente fracos - ou, para ser mais exato, inexistente. (...) Com isso, deixamos a África. Não vamos abordá-la posteriormente, pois ela não faz parte da história mundial; não tem nenhum movimento ou desenvolvimento para mostrar. (HEGEL, Georg Wilhelm Friedrich. Filosofia da história. Brasília: Ed. UnB, 1995, p. 84-88).
} 
acaba centrando-se no intuito de desconstrução da visualidade racializada que embalou e embala o ocidente. Eles assim o fazem, tal como o faz Michaud, demonstrando como tais critérios fazem parte do atual momento histórico marcado pelas estruturas e práticas racializadas.

É significativo que a obra se encerre abordando a arte contemporânea, afinal, as perguntas que fazemos ao passado são fruto das preocupaçóes que temos com o presente. Em suma e ao final da leitura, a obra provoca os historiadores da arte a se colocarem uma questão capital: como pensar a historicidade da arte e sua narrativa fora do âmbito genealógico das filiações?

As invasóes bárbaras apresenta uma grande contribuição à historiografia da arte, não apenas porque traz, com erudição, uma pesquisa excelentemente realizada, mas porque dialoga com as mais agudas preocupaçóes $\mathrm{da}$ contemporaneidade. Se hoje sobra à História o exercício da autocrítica e da reflexão sobre sua própria escrita, faltava à História da Arte a coragem de se colocar algumas questóes difíceis e incontornáveis impostas por nosso presente. Neste livro, Michaud realiza uma reflexão preciosa sobre a história, a ética e a estética da história da arte e as representaçóes e sentimentos fundantes desta disciplina. Para quem se interessa por temas ligados não só à História da Arte, mas às questóes ligadas à visualidade, em especial ao regime de visualidade racializado, esta obra é leitura imprescindível, e por isso espero que não tardemos a ver uma tradução em português.

\section{Como citar}

MICHAUD. Éric. Les invasions barbares: Une généalogie de l'histoire de l'art. Paris: Gallimard, 2015. p. 320. Resenha de DOSSIN, Francielly Rocha. O imaginário europeu sob o fantasma da filiação: Sobre a racialização da arte e sua história. Topoi. Revista de História, Rio de Janeiro, v. 18, n. 36, p. 690-695, set./dez. 2017. Disponível em: <www.revistatopoi.org>. 